\title{
Delivery of antigen-encoding plasmid DNA into the cytosol of macrophages by attenuated suicide Listeria monocytogenes
}

\author{
Guido Dietrich ${ }^{1,6}$, Andreas Bubert', ${ }^{1,6}$ Ivaylo Gentschev', Zeljka Sokolovic', Andreas Simm², Andre Catic ${ }^{3}$, \\ Stefan H.E. Kaufmann ${ }^{3,4}$, Jürgen Hess ${ }^{3,4}$, Aladar A. Szalay ${ }^{1,5}$, and Werner Goebel ${ }^{1, *}$
}

'Lehrstuhl für Mikrobiologie and 'Department of Physiological Chemistry, University of Würzburg, D-97074 Würzburg, Germany. ${ }^{3}$ Department of Immunology, University

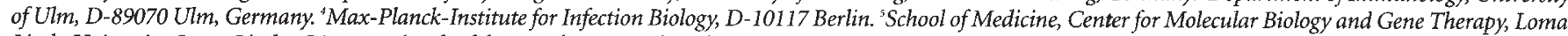
Linda University, Loma Linda, CA 92350. ${ }^{6}$ Both of these authors contributed equally to this work. ${ }^{*}$ Corresponding author (e-mail: goebel@biozentrum.uni-wuerzburg.de).

Received 13 August 1997; accepted 20 November 1997

\begin{abstract}
Eukaryotic expression vectors can be delivered to macrophages using attenuated self-destructing Listeria monocytogenes. L. monocytogenes cells are preferentially lysed in the host cell macrophage cytosol by the production of a $\mathbf{P}_{\text {act }}$-dependent Listeria-specific phage lysin. Efficient expression of the cloned reporter genes by the macrophages and subsequent antigen presentation were achieved after the delivery of eukaryotic expression vectors by the attenuated suicide $L$. monocytogenes strain. After delivery by $L$. monocytogenes plasmid DNAs were found to integrate into the macrophage cell's genome at a frequency of about $10^{-7}$.
\end{abstract}

Keywords: vaccine development, DNA-delivery, plasmid-integration

\begin{abstract}
Vaccination by intramuscular injection of antigen-encoding DNA is a promising new approach ${ }^{1-4}$, but the mechanism(s) by which an immune response is accomplished is not fully understood. Bone marrow-derived antigen presenting cells (APCs), rather than myocytes, seem to induce the immune responses after migration to the spleen ${ }^{5}$. Because of the low numbers of APCs in muscle, protection against infectious agents by intramuscular injection of plasmid DNA may only be possible using very potent antigens. This makes it desirable to deliver the antigen-encoding DNA directly to splenic APCs.

Recently, attenuated Shigella flexneri ${ }^{\star}$ and invasive Escherichia coli were used for plasmid delivery in cultured mammalian cells, guinea pigs, and mice. We report on the development of Listeria monocytogenes as a DNA-delivery vehicle. $L$. monocytogenes is a gram-positive, facultative intracellular bacterium. As opposed to gram-negative bacteria, L. monocytogenes lacks lipopolysaccharide (LPS) and is also able to invade a wider range of mammalian cells, replicating in the cytosol $^{8}$. Because it invades its host through the intestinal mucosal surface, $L$. monocytogenes is a candidate for oral vaccination. Shortly after infection, bacteria are found in the spleen where professional APCs are abundant. Delivery of plasmid DNA to those cells therefore should be significantly enhanced by the use of suitably constructed $L$. monocytogenes. We used attenuated $L$. monocytogenes cells, which undergo self-destruction in the cytosol of infected macrophages by the production of a $\mathrm{P}_{\text {act }}$-dependent phage lysin. Lysis results in the release of plasmid DNA, which carries different heterologous genes under the control of the human cytomegalovirus major immediateearly promoter/enhancer region $\left(\mathrm{P}_{\mathrm{CMV}}\right)$. After the delivery of the eukaryotic expression vectors by the attenuated suicide $L$. monocytogenes strain, both efficient expression of the cloned genes by the macrophages and antigen presentation were achieved.
\end{abstract}

\section{Results}

Attenuation of $L$. monocytogenes. The attenuated L. monocytogenes mutant strain $\Delta 2$, which was mainly used in this study, is a derivative of the fully virulent wild-type strain L. monocytogenes EGD. The mutant, which lacks the entire lecithinase operon consisting of the genes $m p l$, act $A$, and $p l c B$ (ref. 9), invades host cells and is released into the cytosol of the infected cells with efficiencies similar to the wild-type strain, but is impaired in intra- and intercellular movement (Fig. 1A) similar to an $a c t A$ mutant ${ }^{10}$. Furthermore, it appears to cause less inflammatory reaction than the wild-type strain or an act $A$ mutant ${ }^{9}$. Infection of $\mathrm{BALB} / \mathrm{c}$ mice with the $\Delta 2$ mutant yields an intravenous $\mathrm{LD}_{50}$ that is three orders of magnitude higher than that of wild-type $L$. monocytogenes EGD (i.e., $1 \times 10^{7}$ bacteria for $\Delta 2$ compared with $1 \times 10^{4}$ for EGD).

The listerial promoter $\mathbf{P}_{a c t A}$ is activated in the host cell's cytosol. The genes act $A$ and $p l c B$ of $L$. monocytogenes are transcribed from promoter $\mathrm{P}_{\text {act }}$ under the control of the transcription activator PrfA, which regulates most of the known virulence genes of $L$. monocytogenes. The promoter $\mathrm{P}_{\text {acts }}$ is preferentially activated in the cytosol of the infected host cells (data not shown). We inserted the $g f p$ gene $^{11}$ behind $\mathrm{P}_{\text {act }}$ into the shuttle vector pLSV16. The wild-type strain and the $\Delta 2$ mutant bacteria carrying the $\mathrm{P}_{\text {act }}-g f p$ plasmid did not show significant fluorescence when the bacteria were grown in brain-heart infusion (BHI) medium (data not shown). Fluorescent bacteria were, however, observed when the two listerial strains (EGD and the $\Delta 2$ mutant, carrying $\mathrm{P}_{\text {act }}-g f p$ ) were used to infect the macrophage-like cell line $\mathrm{P}_{388} \mathrm{D}_{1}$ (Fig. 1A). Under these conditions fluorescence of the bacteria was observed approximately $3 \mathrm{~h}$ postinfection (p.i.), i.e., at a time when most intracellular listeriae are localized in the host cell's cytosol ${ }^{10}$. Fluorescence remained at a high level for at least $10 \mathrm{~h}$. As expected, the wild-type bacteria spread into neighboring cells $6 \mathrm{~h}$ p.i. ${ }^{10}$, whereas the $\Delta 2$ mutant accumulated as microcolonies within the infected cells.

Intracellular self-destruction of $L$. monocytogenes. The lysis protein PLY118 is a late gene product of the Listeria bacteriophage A118 necessary for the release of progeny phage. PLY118 is a cell 
A
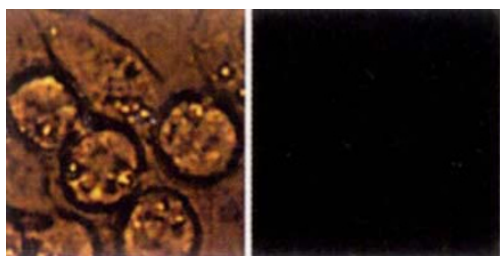

$\Delta 2$

$1 \mathbf{h}$

J774A.1

B

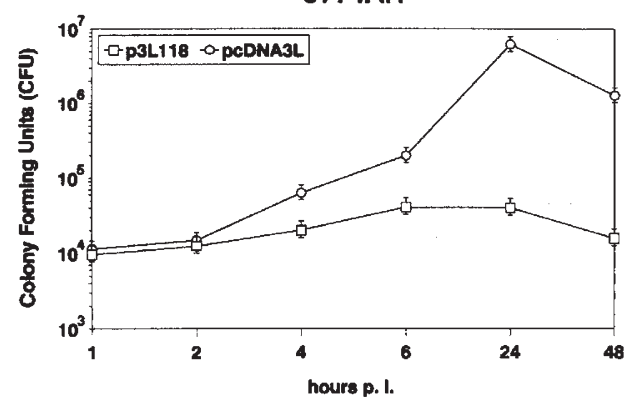

C

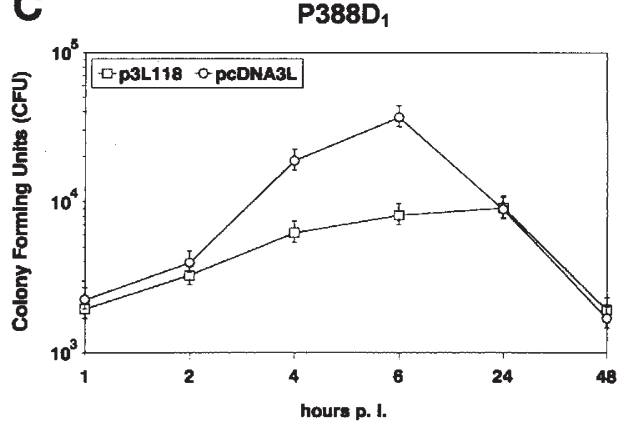

Figure 1. Expression of the cDNA for gfp and the ply118-gene under the control of the actA-promoter of $L$. monocytogenes in bacteria during infection of macrophages. (A) GFP. expressing listeriae (EGD or $\Delta 2$ carrying $P_{\text {act }}-g f p$ ) in infected P388D, macrophages after infection in complete medium at an MOI of 10:1. At different time intervals the fluorescent bacteria were analyzed microscopically. (B and C) Inactivation of $L$. monocytogenes mutant $\Delta 2$ in the cytosol of infected macrophages by intracellular expression of ply118 under control of $P_{\text {scta. }}$ Macrophage cell lines (B) J774A.1 and (C) P388D, were infected with $\Delta 2$ (p3L118) and $\triangle 2$ (pcDNA3L) at an MOl of $1: 1\left(\sim 2.5 \times 10^{4}\right.$ macrophages per well). Combined viable bacterial counts from three independent experiments are shown.

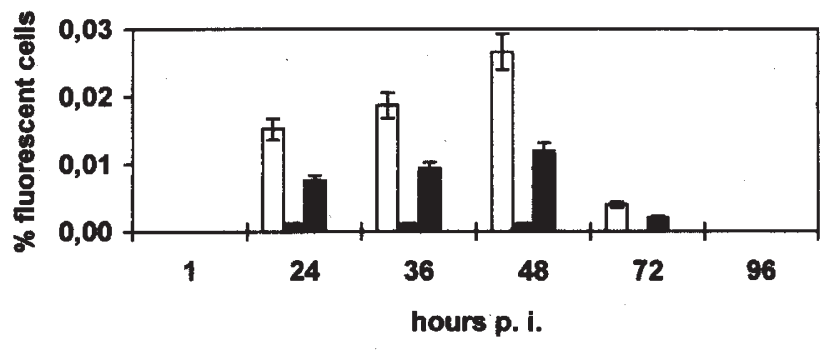

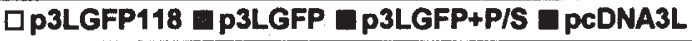

Figure 2. Expression of GFP in macrophages using $L$. monocytogenes-mediated plasmid DNA delivery. P388D, cells were infected with $L$. monocytogenes mutant $\Delta 2$ carrying plasmids P3LGFP118; P3LGFP, in the presence or absence of penicillin and streptomycin $(\mathrm{P} / \mathrm{S})$, and the control plasmid pcDNA3L. One million macrophages per flask were infected with bacteria at an MOI of 50:1. Cells expressing GFP were determined by fluorescence microscopy of at least $5 \times 10^{4}$ cells per flask at each time point. Combined data of two replicate experiments are shown.

wall-hydrolyzing enzyme specific for Listeria ${ }^{12}$. To cause self destruction of $L$. monocytogenes within host cells, the gene ply118 (encoding PLY118) was cloned downstream of the actA promoter and inserted into plasmid pcDNA3L to yield $\mathrm{p} 3 \mathrm{~L} 118$. As expected, the $\Delta 2$ mutant carrying the plasmid p3L118 was not affected when the bacteria were grown in BHI. Rapid lysis of the bacteria occurred, however, in the cytosol of infected $7774 \mathrm{~A} .1$ and $\mathrm{P}_{388 \mathrm{D}_{1}}$ macrophages (Fig. 1B and C). The control strain carrying pcDNA3L multiplied for $24 \mathrm{~h}$ in the cytosol of J774A. 1 cells and for only $6 \mathrm{~h}$ in P388D, cells. The reason for the observed decrease in the number of viable bacteria in $\mathrm{P} 388 \mathrm{D}_{1}$ cells between $6 \mathrm{~h}$ and $24 \mathrm{~h}$ p.i. is presently unknown. A possible explanation may be a higher bactericidal activity of the $P 388 D_{1}$ macrophages compared with J774A.1 and/or an enhanced lysis of the infected $P 388 \mathrm{D}_{1}$ cells and the subsequent killing of the released extracellular bacteria in the gentamicin-containing medium, an effect that also has been observed by others when macrophage cells were infected with $a c t A$ or $p l c B$ mutants ${ }^{13,14}$. The difference in the intracellular growth rate between Listeria carrying p3L118 and

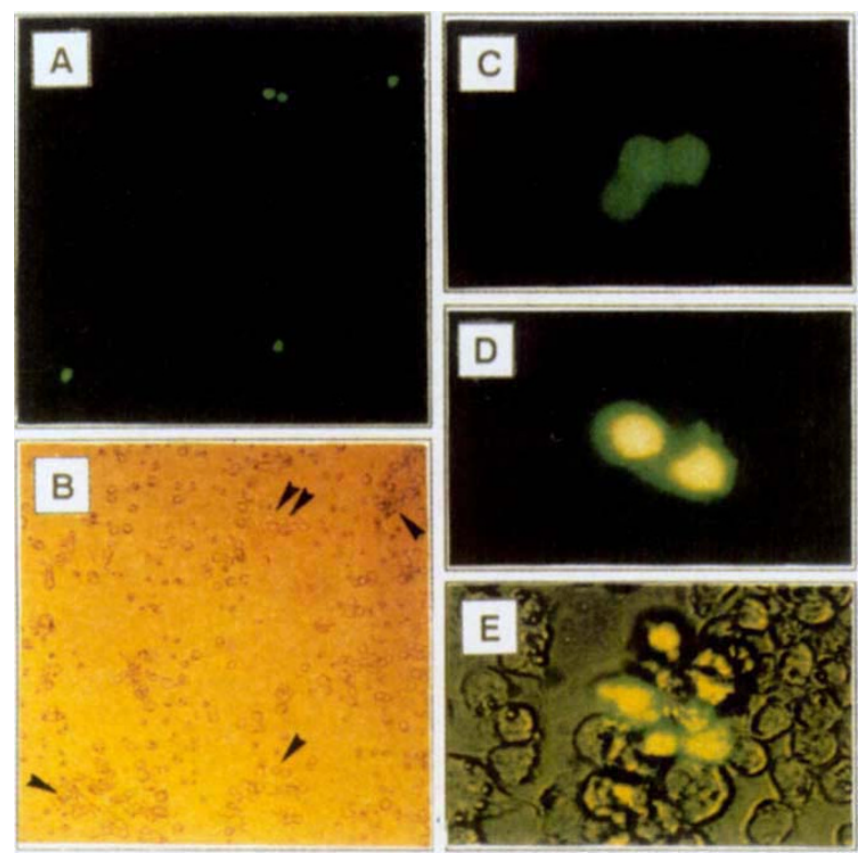

Figure 3. Detection of GFP-expression in P388D, $_{\text {, cells after infection }}$ with $\Delta$ 2(p3LGFP118). (A) Fluorescence microscopic image and (B) light microscopic image of the same field are shown $48 \mathrm{~h}$ p.i. Arrows indicate positions of fluorescing cells. (C-E) P388D, cells 72 h p.i. (C and D) Images from fluorescence microscopy. (E) Image from combined light and fluorescence microscopy.

those carrying pcDNA3L appears $2 \mathrm{~h}$ p.i., when the bacteria are predominantly in the host cell's cytosol, the compartment where $\mathrm{P}_{\text {act }}$ is activated, allowing the synthesis of the lysin. The difference in viable bacterial counts between $\Delta 2(\mathrm{p} 3 \mathrm{~L} 118)$ and $\Delta 2$ (pcDNA3L) is about one log order of magnitude in both macrophage cell lines after $6 \mathrm{~h}$ of intracellular growth. This difference increases to more than two orders of magnitude in J774A.1 24 h p.i., indicating an efficient cytosol-activated production of lysin resulting in self-destruction of the p3L118-carrying bacteria. 


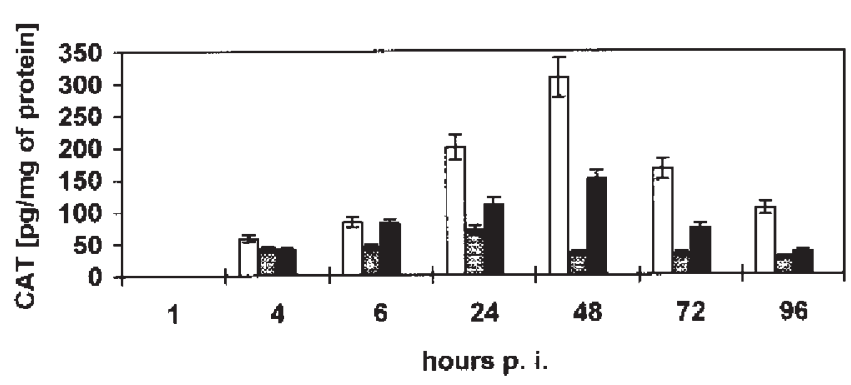

Figure 4. CAT-expression in P3B8D, cells infected with $L$. monocytogenes strain $\Delta 2$ harboring plasmids p3LCAT118 $\square$, p3LCAT (with and without $\square$ addition of penicillin and streptomycin) and control plasmid pcDNA3L Combined CATactivities of two replicate experiments are shown.

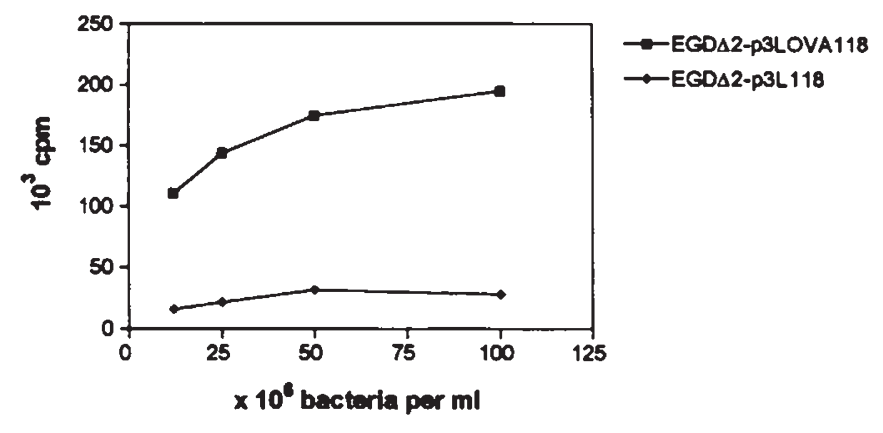

Figure 5. Presentation of the OVA-epitope (257-264) after delivery by $\triangle 2$ (p3LOVA118). MHC class I presentation of the OVA (257-264) H2K'-epitope of ovalbumin was determined by interleukin-2 (IL-2) 8ecretion of OVA-specific RF33.70 T-T hybridoma cells. Secreted IL2 was quantified by ' $\mathrm{H}$-thymidine incorporation of $\mathrm{IL}-2$-dependent CTLL cells.

Plasmid-delivery by $L$. monocytogenes. We reasoned that PLY118-mediated cytosolic lysis of L. monocytogenes should lead to efficient release of DNA into the cytosol of the macrophages. Plasmid-borne genes under the control of $\mathrm{P}_{C, M}$ could then be expressed in the infected host cells. Plasmids p3LGFP118, p3LCAT118, and p3LOVA118, which carry either $g f p$ (encoding humanized GFP's), cat (encoding chloramphenicol acetyl transferase [CAT]), or part of the ova gene (encoding the T cell-reactive $\mathrm{H}-2 \mathrm{~K}^{\mathrm{b}}$ epitope [OVA 257-264], from chicken ovalbumin ${ }^{16}$ ) under the control of $\mathrm{P}_{\mathrm{CMV}}$ on an otherwise identical vector plasmid, were constructed. Strains containing similar plasmids without ply 118 (p3LGFP, p3LCAT, and p3LOVA) were used as controls. The functional integrity of the plasmids was tested by the transient transfection of L929 cells with p3LGFP118, p3LGFP, p3LCAT118, and p3LCAT. We found that $\mathrm{P} 388 \mathrm{D}$, macrophages exhibited consistently higher levels of GFP- and CAT-expression than J774A.1 cells upon transfection. Therefore, we used the P388D, cell line for all subsequent experiments.

$\mathrm{P} 388 \mathrm{D}$, macrophages were infected with $L$. monocytogenes mutant $\Delta 2$ (Fig. 2) carrying the plasmids p3LGFP1 18, p3LGFP, and pcDNA3L, respectively, at a multiplicity of infection (MOI) of 50:1. One hour p.i. most of the macrophages contained one bacterium per host cell on average. The number of intracellular bacteria that carried the plasmid without ply 118 increased with time, whereas that of bacteria carrying the plasmid with $\mathrm{P}_{\text {acc }}$-ply 118 remained at the initial level in the infected macrophages. The effect of the lysin on bacterial killing in the infected macrophages was significant ( $>90 \%$ of the bacteria were killed $6 \mathrm{~h}$ p.i.), but did not reach the
A
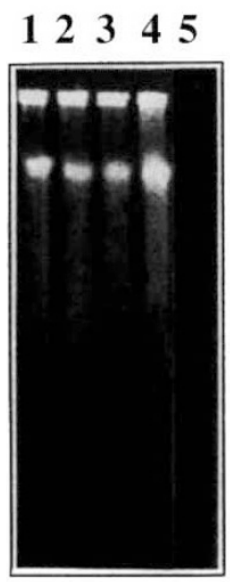

B
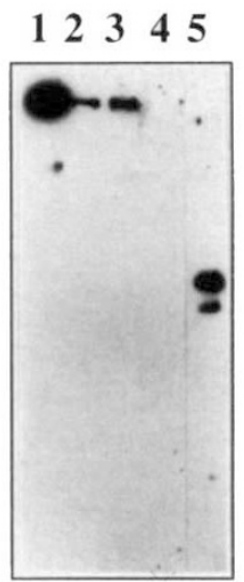

12345

Figure 6. Analysis of integration of plasmid p3LCAT into the genome of P388D, macrophages by nucleic acid hybridization. (A) Analysis by digestion of genomic DNA with Srfi, pulse fleld gel electrophoresis. (B) Southern blot analysis with a "P-labeled p3LCAT probe. Lanes 1-3: DNA of three independently obtained G418-resistant P388D,

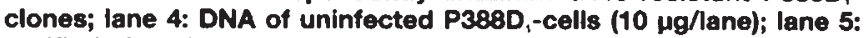
purifled plasmid p3LCAT $(0.1 \mathrm{ng})$; all treated with Srfi. (C) Southern blot analysis of DNA from three independently obtained G418resistant P388D,-clones with a "P-labeled p3LCAT probe. Lanes 1-3: DNA of three G418-resistant P388D,-clones; lane 4: DNA of uninfected P388D,-cells (10 $\mu \mathrm{g} /$ /ane); lane 5: purified plasmid p3LCAT (0.1 ng), all digested with Pstl.

level attained by treatment with the antibiotics penicillin and streptomycin (which killed $>99 \%$ of the bacteria within $6 \mathrm{~h}$ p.i.). About $0.03 \%$ of the macrophages infected with $\Delta 2$ (p3LGFP118) showed GFP-expression between 24 to $48 \mathrm{~h}$ p.i. The fluorescence in the GFP-expressing macrophages was distributed over the entire cytosol (Fig. 3) and not concentrated in the bacteria as observed when GFP was expressed under the control of $P_{a c m}$ (Fig. 1A). This finding indicates that the plasmid was transferred to the macrophages via the bacteria and that GFP was indeed expressed by the host cells. Infection with strain $\Delta 2$ (p3LGFP) resulted in GFPexpression in about $0.001 \%$ of the macrophages while infection with the control strain $\Delta 2(\mathrm{pcDNA} 3 \mathrm{~L})$ did not show expression. Hence, efficient delivery of plasmid DNA into the cytosol of host cells by $L$. monocytogenes is stimulated by self-destruction of the bacteria by expression of PLY118 in the host's cytosol. Beside the advantages of avoiding the use of antibiotics, lysin-mediated plasmid release seems to be an efficient method comparable to eliminating the bacteria by antibiotic treatment. We found that about $0.01 \%$ of the macrophages infected with mutant $\Delta 2$ (p3LGFP) expressed GFP after treatment with penicillin and streptomycin. In this experiment, most of the macrophages again contained on average one bacterium per host cell $1 \mathrm{~h}$ p.i. When the wild-type strain EGD was used in similar experiments for the delivery of plasmid p3LGFP118, the frequency of successful plasmid transfer was even higher (i.e., $>0.2 \%$ of macrophages expressed GFP; data not shown). Extracellular addition of the plasmids p3LGFP118 or p3LGFP to $1 \times 10^{7} \mathrm{P} 388 \mathrm{D}$, macrophages does not lead to GFPexpressing transfectants, demonstrating the transfection efficiency of the listerial delivery system.

Macrophages expressing GFP after plasmid-delivery by mutant $\Delta 2$ (p3LGFP) are able to proliferate (Fig. $3 \mathrm{C}-\mathrm{E}$ ) and can be isolated by fluorescence-activated cell sorting (FACS) followed by culturing in fresh media. We observed a gradual loss of fluorescence with prolonged culture time, which was not altered by addition of cyclohex- 
imide or proteasome inhibitors, suggesting that the relatively low percentage of GFP-expressing macrophages is not due to a high instability of GFP in these cells.

$\mathrm{P} 388 \mathrm{D}_{1}$ macrophages were infected with mutant $\Delta 2$ carrying different CAT-expression vectors at an MOI of 50:1, leading to infection of most host cells with one bacterium per host cell on average. CATactivities peaked at $48 \mathrm{~h}$ p.i., and lysis of the bacteria by expression of PLY118 led to the most efficient CAT-expression (Fig. 4).

Antigen-presentation after L. monocytogenes-mediated plasmiddelivery. To test the efficiency of antigen presentation by macrophages after delivery of the antigen-encoding plasmid by listeriae, we used the $\Delta 2$ mutant carrying the plasmid p3LOVA118. This plasmid contains part of the ova gene encoding the $\mathrm{H}-2 \mathrm{~K}^{\mathrm{b}}$ epitope (OVA 257-264) from chicken ovalbumin ${ }^{16}$. Efficient presentation of this epitope in the context of major histocompatibility (MHC) class I occurred in bone marrow-derived macrophages because the OVAspecific T-cell hybridoma RF33.70 (ref. 16) recognized macrophages infected with $\Delta 2$ (p3LOVA118), but not macrophages infected with $\Delta 2$ (pcDNA3L) (Fig. 5).

Integration of plasmid molecules in the genome of macrophage cells. One major problem arising from DNA-vaccination is the possible integration of plasmid DNA into the host genome. To investigate this question, we took advantage of the neomycin phosphotransferase II gene (neo) carried on the vector pcDNA3, which was part of each vector construct. Infection of $\mathrm{P} 388 \mathrm{D}$, cells with $\Delta 2$ (p3LCAT) at an MOI of 50:1 leads to the infection of most of the host cells. Selection on G418 resulted in resistant macrophage clones, which were maintained under selective conditions for over 12 weeks. In all clones plasmid p3LCAT was detected in macrophage chromosomal DNA by Southern blot hybridization with radioactively labeled p3LCAT; while no such sequences were present in the chromosomal DNA of uninfected P388D $\mathrm{D}_{1}$ cells. When the total DNAs of three different clones were cleaved with Srfl (which does not cleave vector p3LCAT) and the fragments were separated by pulse-field gel electrophoresis (Fig. 6A), a single, large-sized fragment (always larger than $1 \mathrm{Mbp}$ ) hybridizing with the probe was detected in each case (Fig. 6B). Free purified vector DNA showed two bands (probably supercoiled and open circular form) of higher mobility under these conditions. Each of the three analyzed clones exhibited a different intensity in the "plasmid-hybridizing" large DNA-fragment, suggesting different multiple copies of the plasmid DNA incorporated into the host's genome. Analysis of the genomic DNAs after cleavage with PstI, which cleaves the plasmid DNA into two fragments (Fig. 6C), resulted in the same two fragments, exhibiting the same hybridization intensities as the uncleaved large chromosomal fragments resulting from the Srfl-digestion. This finding strongly suggests that multiple plasmid copies are integrated into the host cell genome in tandem arrangement. The flanking sequences resulting from PstIdigestion could not be detected, probably due to their single copy number. The rate of integration in $\mathrm{P} 388 \mathrm{D}_{1}$ macrophages was about $10^{-7}$, as calculated by three independent experiments in which macrophage cells were initially infected at a rate of about one bacterium per cell. These data show that plasmid DNA of the type commonly used in DNA vaccination may well integrate into the genome of transfected host cells.

\section{Discussion}

The use of an attenuated strain of $L$. monocytogenes as a plasmid DNA delivery system is a new approach to the original DNA vaccination strategy ${ }^{1-4}$ and to the recently described alternatives ${ }^{6,7}$. The attenuated L. monocytogenes carrier strain (devoid of LPS and other highly toxic materials) can be given orally. It interacts with the intestinal mucosa at an early stage and may subsequently introduce the plasmids directly into phagocytic host cells, mainly professional APCs in the spleen. The efficiency of the release of plasmid DNA into the host cell's cytosol is enhanced by the expression of the Listeria-specific lysin under the control of the intracellularly activated actA-promoter, resulting in self-destruction of the bacteria. This procedure avoids the use of antibiotics and is superior to antibiotic-treatment-based release of the plasmid DNA. There may be two reasons for the difference in the observed numbers of infected macrophage cells and those expressing GFP: (1) only some of the attenuated bacteria infecting the host cells survive the antimicrobial milieu inside the phagosome and are able to escape into the host cell $\mathrm{cytosol}^{17}$, whereas the others are totally digested, including the plasmid DNA; and (2) not all listeriae being taken up reach the host cell cytosol as an intact viable entity, but the plasmid DNA is still released into this compartment. This may be reflected by the observation that the attenuated $\Delta 2$ mutant strain is able to deliver plasmid DNA without PLY118-mediated autolysis, albeit with lower efficiency (Fig. 2 and 4). The released plasmid molecules may be subject to degradation during bacterial lysis or by host-cell nucleases. Apart from enhancement of plasmid release, the coexpression of the lysin adds to the safety of the attenuated $L$. monocytogenes mutant $\Delta 2$ by considerably lowering the number of viable bacteria.

Among the safety problems that may arise as a result of DNA vaccination, the integration of the applied plasmid DNA into the host cell's chromosomes is of major concern $n^{1,2,18,19}$. No integration was observed when plasmid DNA was injected into mouse muscle tissue even though this DNA had persisted for more than 19 months ${ }^{20}$. Two different studies indicate, however, a possible integration of heterologous DNA into the host cell's genome when plasmid DNA was delivered to cultured mammalian cells by $E$. coli or when M13mp18 DNA was ingested orally by mice ${ }^{21}$. The data reported here show that the plasmid p3LCAT, which is a derivative of the eukaryotic expression vector pcDNA3 commonly used for DNA vaccination, is able to integrate into the genome of the macrophage cell line $\mathrm{P} 388 \mathrm{D}_{1}$ at a frequency of about $10^{-7}$. This unexpectedly high frequency of plasmid integration may be due to the high plasmid copy number delivered to most of the infected cells and may not generally hold true for all DNA vaccination strategies. It indicates, however, that integration of such plasmids may occur, which might create problems in the application of DNA-vaccines. On the other hand, intramuscular immunization with DNA encoding strong antigens seems to lead to destruction of most of the antigen-expressing myofibers due to a CD8+ T-cell response against the antigen ${ }^{22}$. The delivery of the plasmid DNA by the attenuated $L$. monocytogenes strain may even increase this effect as phagocytic and nonphagocytic cells of the vaccinated host which are infected by L. monocytogenes, will evoke a strong cytotoxic T lymphocyte response due to the presence of listerial p60 and listeriolysin in these cells ${ }^{23,24}$. Both proteins have been shown to contain immunodominant T-cell epitopes that are presented in the context of MHC class I. Therefore, host cells infected by L. monocytogenes, including those with integrated plasmid sequences, finally should be eradicated by the cellular immune system, thereby reducing the risk possibly associated with genomic plasmid integration.

\section{Experimental protocol}

Bacterial strains. Deletion mutant $\Delta 2$ of wild-type L. monocytogenes strain EGD Svl/2a lacks the genes $m p l$, act $A$, and $p l c B$. Plasmids used are described in Table 1.

Mammalian cell culture and infection. The macrophage-like cell lines P388D, and J774A.1 were cultured in RPMI 1640 medium (Gibco BRL, Paisley, UK) supplemented with $10 \%$ heat-inactivated FCS (Gibco) and $2 \mathrm{mM}$ L-glutamine (Gibco), referred to as complete medium, at $37^{\circ} \mathrm{C}$ in a humified $5 \% \mathrm{CO}$ atmosphere. Macrophage cells were infected with logarithmically growing bacteria. After incubation for $60 \mathrm{~min}$, extracellular bacteria were removed by washing the cultured cells three times with PBS. For selective removal of extracellular bacteria, the infected macrophages were routinely cultured in the presence of 10 $\mu \mathrm{g} / \mathrm{ml}$ gentamicin. To some infections, penicillin $(100 \mathrm{IU} / \mathrm{ml})$ and streptomycin $(100 \mu \mathrm{g} / \mathrm{ml})$ (P/S; Gibco) were added from $2 \mathrm{~h}$ p.i. onwards to lyse 
Table 1. Plasmids.

\begin{tabular}{|c|c|c|c|}
\hline Vector & Backbone & $\begin{array}{c}\text { Resistance } \\
\text { marker }\end{array}$ & $\begin{array}{c}\text { Transcription } \\
\text { units }\end{array}$ \\
\hline $\begin{array}{l}P_{\text {set }}-g f p \\
\text { PCDNA3L }\end{array}$ & $\begin{array}{l}\text { pLSV16 (ref. 25) } \\
\text { pcDNA3 (Invitrogen), } \\
\text { L. monocytogenes ori }\end{array}$ & $\begin{array}{l}\text { tet } \\
\text { tet }\end{array}$ & $\begin{array}{l}P_{\text {sus }}-g f p \\
P_{\text {sveo }}-n \theta 0\end{array}$ \\
\hline p3L118 & PCDNA3L & tet & $P_{\text {ociA }}-$ ply 118 \\
\hline p3LGFP118 & PCDNA3L & tet & $\mathrm{P}_{\text {cen }}-p l y 118, \mathrm{P}_{\mathrm{con}}-g f p$ \\
\hline p3LCAT118 & PcDNA3L & tet & $\mathrm{P}_{\mathrm{eu}}-$ ply 118, $\mathrm{P}_{\mathrm{cuv}}-$ cat \\
\hline p3LOVA118 & PCDNA3L & tet & $\mathrm{P}_{\mathrm{axu}}-$ ply 118, $\mathrm{P}_{\mathrm{cMv}}$-ova \\
\hline p3LGFP & PCDNA3L & tet & $\mathrm{P}_{\mathrm{cur}}-g f p, \mathrm{P}_{\mathrm{sv}}-n e 0$ \\
\hline p3LCAT & pcDNA3L & tet & $P_{\text {cav }}$-cat, $P_{\text {sval }}-$ neo \\
\hline p3LOVA & pcDNA3L & tet & $\mathbf{P}_{\mathrm{CMV}}$-ova, $\mathrm{P}_{\mathrm{Sv} 40}-$ neo \\
\hline
\end{tabular}

intracellular bacteria. During long-term infections, media were changed every $24 \mathrm{~h}$.

Determination of viable bacterial counts. Infections were done in complete medium containing $10 \mu \mathrm{g} / \mathrm{ml}$ tetracycline (Sigma, St. Louis, MO). Macrophage cells were incubated for $60 \mathrm{~min}$, washed three times with PBS, and cultured in complete medium supplemented with $10 \mu \mathrm{g} / \mathrm{ml}$ gentamicin (Boehringer Mannheim, Mannheim, Germany) and $10 \mu \mathrm{g} / \mathrm{ml}$ tetracycline. Macrophages were lysed as indicated and viable bacterial counts determined by plating serial dilutions on $\mathrm{BHI}$-agar.

Transfection of mammalian cells. Transfections were done with the Transfection MBS Mammalian Transfection Kit (Stratagene, La Jolla, CA), in accordance with the manufacturer's instructions. Cells were assayed $48 \mathrm{~h}$ posttransfection for GFP- or CAT-activity, respectively.

Cell sorting. Macrophages expressing GFP were sorted with an Epics Elite ESP cell sorter (Coulter, Krefeld, Germany). GFP-fluorescence was analyzed using a 515- to $535-\mathrm{nm}$ bandpass filter and excitation with the $488-\mathrm{nm}$ line of an Argon laser. Cells sorted as positive had a more than 25 -fold increase in fluorescence.

Determination of CAT-activity. Cells were harvested and CAT-activities of cell lysates containing $100 \mu \mathrm{g}$ of total protein were determined in accordance with the manufacturer's instruction (Invitrogen, Carlsbad, CA). Protein concentrations had been measured with the Bradford assay (Bio-Rad, Hercules, CA). Purchased CAT-enzyme (Boehringer) was used for generation of a standardization curve for the activity of pure enzyme.

Proliferation assay of OVA-specific T-cells. Bacteria were added to adherent C57BI./6-derived bone marrow macrophages (10' per well), which were previously cultured in Dulbecco's modified Eagle's medium (DMEM including $10 \%$ FCS, $2 \mathrm{mM} \mathrm{L}$-glutamine, $1 \mathrm{mM}$ sodium pyruvate) containing $500 \mathrm{U} / \mathrm{ml}$ interferon gamma and $10 \mu \mathrm{g} / \mathrm{ml}$ tetracycline for $24 \mathrm{~h}$. After phagocytosis for $1 \mathrm{~h}, 50$ $\mu \mathrm{g} / \mathrm{ml}$ gentamicin was added and the infected macrophages were incubated at $37^{\circ} \mathrm{C}$ in the presence of $10 \% \mathrm{CO}_{2}$ for $24 \mathrm{~h}$. The cells were washed three times and fixed in $1 \%$ paraformaldehyde in PBS. RF33.70 T-T hybridoma cells specific for OVA (257-264)- $\mathrm{K}^{\mathrm{b}}$ ( $10^{5}$ per well) were then added in RPMI 1640 supplemented with $10 \%$ FCS, $2 \mathrm{mM} \mathrm{L}$-glutamine and $50 \mu \mathrm{g} / \mathrm{ml}$ gentamicin for $24 \mathrm{~h}$. The amount of secreted interleukin-2 (IL-2) after $48 \mathrm{~h}$ was quantified by ' $\mathrm{H}$ thymidine incorporation of IL-2-dependent CTLL cells as described ${ }^{16}$.

Analysis of plasmid integration into macrophage genomic DNA. Macrophage cells were infected with $\Delta 2$ (p3LCAT) at an MOI of 50:1. Medium was supplemented with gentamicin $(10 \mu \mathrm{g} / \mathrm{ml})$, tetracycline $(10 \mu \mathrm{g} / \mathrm{ml})$, penicillin $(100 \mathrm{IU} / \mathrm{ml})$, and streptomycin $(100 \mu \mathrm{g} / \mathrm{ml}) 2 \mathrm{~h} \mathrm{p.i.,} \mathrm{and} \mathrm{with} \mathrm{G418}(600$ $\mu \mathrm{g} / \mathrm{ml} ; \mathrm{Gibco}$ ) on day 5 . The macrophage cells were maintained with daily changes of media, until colonies resistant to $\mathrm{G} 418$ were detected and harvested individually. The clones were grown to confluency under selective conditions. On day 90 p.i., inserted plasmid p3LCAT was assayed by nucleic acid hybridization after pulse-field gel electrophoresis or agarose gel electrophoresis. Macrophage cells were embedded in agarose and treated with Proteinase $\mathrm{K}$ (Merck, Darmstadt, Germany). Subsequently, DNA was digested with Srfl, separated by pulse-field gel electrophoresis, transferred to Hybond $\mathrm{N}$ membrane and hybridized to BamHI-linearized, "P-labeled p3LCAT vector. Alternatively, genomic DNA was isolated, digested with PstI, separated by agarose gel electrophoresis, and blotted and hybridized to BamHI-linearized, "P-labeled p3LCAT vector.

\section{Acknowledgments}

We thank J. Daniels, M. Dietrich, R. Gross, A. Haas, and S. Schlör for critical reading of the manuscript, and $M$. Kuhn and S. Grötsch for helpful discussions. We also wish to thank S. Niewisk and B. Schlereth for help with $L D_{x}$-determination of L. monocytogenes mutant $\Delta 2, G$. Blum-Oehler and B. Janke for help with pulse-field electrophoresis, M.J. Loessner for providing vector $\mathrm{pHPL118}$, B.P. Cormack for vector $p K E N 2$, and A. Schimpl for a generous gift of recombinant IL-2. Supported by the Deutsche Forschungsgemeinschaft (Grants DFG Go 168/16-2, SFB 165-B4, FORGENLI and Fonds der Chemischen Industrie). J.H. and S.H.E.K. are recipients of Grant DFG Ka 573/3-1/2.

1. Donnelly, J.J., Friedman, A., Martinez, D., Montgomery, D.A., Shiver, J.W., Motzel, S.L., et al. 1995. Preclinical efficacy of a prototype DNA vaccine: Enhanced protection against antigenic drift in influenza virus. Nat. Med. 1:583-587.

2. Tascon, R.E., Colston, M.J., Ragno, S., Stavropoulos, E., Gregory, D., and Lowrie, D.B. 1996. Vaccination against tuberculosis by DNA injection. Nat. Med. 2:888-892.

3. Hsu, C.H., Chua, K.Y. Tao, M.H., Lai, Y.L., Wu, H.D., Huang, S.K., et al. 1996. Immunoprophylaxis of allergen-induced immunoglobulin $E$ synthesis and ainway hyperresponsiveness in vivo by genetic immunization. Nat. Med. 2:540-544.

4. Conry, R.M., LoBuglio, A.F., Kantor, J., Schlom, J., Loechel, F., Moore, S.E., et al. 1994. Immune response to a carcinoembryonic antigen polynucleotide vaccine. Cancer Res. 54:1164-1168.

5. Corr, M., Lee, D.J., Carson, D.A., and Tighe, H. 1996. Gene vaccination with naked plasmid DNA: Mechanism of CTL priming. J. Exp. Med. 184:1555-1560.

6. Sizemore, D.R., Branstrom, A.A., and Sadoff, J.C. 1995. Attenuated Shigella as a DNA delivery vehicle for DNA-mediated immunization. Science 270:299-302.

7. Courvalin, P., Goussard, S., and Grillot-Courvalin, C. 1995. Gene transfer from bacteria to mammalian cells. Life Sci. 318:1207-1212.

8. Portnoy, D.A., Chakraborty, T., Goebel, W., and Cossart, P. 1992. Molecular determinants of Listeria monocytogenes pathogenesis. Infect. Immun. 60:1263-1267.

9. Hauf, N., Goebel, W., Fiedier, F., Sokolovic, Z., and Kuhn, M. 1997. Listeria monocytogenes infection of P388D, macrophages results in biphasic NF-kB (RelAp50) activation induced by lipoteichoic acid and bacterial phospholipases and is mediated by $I_{K B} \alpha$ and $I_{K B} \beta$ degradation. Proc. Natl. Acad. Sci. USA 84:9394-9399.

10. Domann, E., Wehland, J., Rohde, M., Pistor, S., Hartl, M., Goebel, W., et at. 1992. A novel bacterial virulence gene in Listeria monocytogenes required for host cell microfilament interaction with homology to the proline-rich region of vinculin. EMBO J. 11:1981-1990.

11. Cormack, B.P. Valdivia, R.H., and Falkow, S. 1996. FACS-optimized mutants of the green fluorescent protein (GFP). Gene 173:33-38.

12. Loessner, M.J., Wendlinger, G., and Scherer, S. 1995. Heterogenous endolysins in Listeria monocytogenes bacteriophages: a new class of enzymes and evidence for conserved holin genes within siphoviral lysis cassettes. Mol. Microbiol. 16:1231-1241.

13. Brundage, R.A., Smith, G.A., Camilli, A., Theriot, J.A., and Portnoy, D.A. 1993. Expression and phosphorylation of the Listeria monocytogenes ActA protein in mammalian cells. Proc. Natt. Acad. Sci. USA 90:11890-11894.

14. Smith, G.H., Marquis, H., Jones, S., Johnston, N.C., Portnoy, D.A., and Goldfine, H. 1995. The two distinct phospholipases $\mathrm{C}$ of Listeria monocytogenes have overlapping roles in escape from a vacuole and cell-to-cell spread. Infect. Immun. 63:4231-4237.

15. Wang, Y., Wang, G., O'Kane, D.J., and Szalay, A.A. 1996. The Renilla luciferasemodified GFP fusion protein is functional in transformed cells. pp. 419-422 in Bioluminescence and chemiluminescence. (Hastings, J.W., Kricka, L.J., and Stanley, P.E. (eds.). John Wiley and Sons, Chichester, UK.

16. Kovacsovics-Bankowsky, M. and Rock, K.L. 1995. A phagosome-to-cytosol pathway for exogenous antigens presented on MHC class I molecules. Science 267:243-246.

17. de Chastellier, C. and Berche, P. 1994. Fate of Listeria monocytogenes in murine macrophages: Evidence for simultaneous killing and survival of intracellular bacteria. Infect. Immun. 62:543-553.

18. Hassett, D.E. and Whitton, J.L. 1996. DNA immunization. Trends Microbiol. 4:307-312.

19. Ertl, H.C.J. and Xiang, Z. 1996. Novel vaccine approaches. J. Immunol. 156:3579-3582

20. Wolff, J.A., Ludtke, J.J., Acsadi, G., Williams, P., and Jani, A. 1992. Long-term persistence of plasmid DNA and foreign gene expression in mouse muscle. Hum. Mol. Genet. 1:363-369.

21. Schubbert, R., Renz, D., Schmitz, B., and Doerfler, W. 1997. Foreign (M13) DNA ingested by mice reaches peripheral leukocytes, spleen, and liver via intestinal wall mucosa and can be covalently linked to mouse DNA. Proc. Natt. Acad. Sci. USA 94:961-966.

22. Davis, H.L., Brazolot Millan, C.L., and Watkins, S.C. 1997. Immune-mediated destruction of transfected muscle fibers after direct gene transfer with antigenexpressing plasmid DNA. Gene Ther. 4:181-188.

23. Harty J.T. and Bevan, M.J. 1992. CD8. T cells specific for a single nonamer epitope of Listeria monocytogens are protective in vivo. J. Exp. Mod. 175:1531-1538.

24. Pamer, E.G. 1994. Direct sequence identification and kinetic analysis of an MHC class I-restricted Listeria monocytogenes CTL epitope. J. Immunol. 152:686-694.

25. Bohne, J., Kestler, H., Uebele, C., Sokolovic, Z., and Goebel, W. 1996. Differential regulation of the virulence genes of Listeria monocytogenes by the transcriptional activator PrfA. Mol. Microbiol. 20:1189-1198. 